\title{
Treatment of focal dystonias of the hand with botulinum toxin injections
}

\author{
LEONARDO G COHEN, MARK HALLETT, BRUCE D GELLER, FRED HOCHBERG
}

From the Human Motor Control Section, Medical Neurology Branch, NINCDS, NIH, Bethesda, MD and Department of Neurology, Massachusetts General Hospital, Harvard Medical School, Boston, MA, USA

SUMMARY The effects of botulinum toxin injections have been studied on 19 patients with hand dystonia. The dystonic muscles were identified by clinical examination and EMG findings of localised bursts of muscle activation with fine wire electrodes during the tasks that precipitated the dystonia. Injections into the most active muscles were given to each patient every 2 weeks in increasing doses (up to $20 \mathrm{U}$ the first week, up to $40 \mathrm{U}$ the second week, and up to $80 \mathrm{U}$ the third week) until performance improvement was achieved. Subjective improvement of cramping, pain and/or tension was associated with temporary weakness in injected muscles. Benefit was seen in 16 patients, lasted between 1 and 6 months, and was reproducible.

Focal dystonias of the hand include a variety of disorders affecting many different skilled functions. They are characterised by muscle spasms and difficulties in fine hand motor control.' The treatment of this syndrome so far has been disappointing. ${ }^{23}$ Different approaches have developed from aetiologic theories. However, there is little support now for psychological theories in the origin of focal dystonias. ${ }^{2}$ Authors considering it a psychoneurotic or psychosomatic disease have tried psychological treatments, ${ }^{4}$ avoidance conditioning, ${ }^{5}$ biofeedback, ${ }^{6}$ and antidepressants. Physical or behavioural therapies have included biofeedback with cutaneous EMG recordings, acupuncture, hypnosis, manipulation, and wax baths. Authors favouring an organic origin have prescribed levodopa, benzhexol, anticholinergics, and sedatives with only transitory benefit. ${ }^{2}$ Lang showed no benefit from IV administration of benztropine, atropine, or chlorpheniramine. ${ }^{7}$ Tenotomy, immobilisation, and percutaneous anti-inflammatories have also failed (Vance cited in ${ }^{2}$ ).

A more recent approach to the treatment of patients with focal dystonias has been the use of botulinum toxin injections. This treatment has proved successful in focal dystonias of the eyes (blepharospasm), ${ }^{8}$ larynx (spasmodic dysphonia) ${ }^{9}$ and neck (spasmodic tor-

Presented in part at the 39th meeting of the AAN New York 1987.

Address for reprint requests: Leonardo G Cohen, MD, National Institutes of Health, NINCDS (Building 10, Room 5N226), Bethesda, MD 20892 USA

Received 10 May 1988 and in revised form 18 August 1988. Accepted 6 September 1988 ticollis). ${ }^{10}$ This paper describes a useful method for treatment of hand cramps with botulinum toxin.

\section{Methods}

Patients participating had a clinical diagnosis of writer's cramp (or musician's cramp) in absence of peripheral nerve or cervical root abnormalities. We studied the effects of botulinum toxin injections on 19 such patients with hand cramps. Excluded were individuals whose EMG and nerve conduction studies demonstrated peripheral nerve or cervical root abnormalities. Four patients who were originally accepted turned out to have electrodiagnostic abnormalities and were excluded from these investigations. Twelve of these

Table 1 Patient characteristics

\begin{tabular}{lllllr}
\hline $\begin{array}{l}\text { Case } \\
\text { No }\end{array}$ & $\begin{array}{l}\text { Age } \\
(y r)\end{array}$ & Sex & Occupation & $\begin{array}{c}\text { Age at } \\
\text { onset } \\
(y r)\end{array}$ & Duration \\
\hline 1 & 59 & F & Accountant & 44 & 15 \\
2 & 31 & M & Policeman & 29 & 2 \\
3 & 35 & M & Attorney & 33 & 2 \\
4 & 39 & M & Guitar player & 35 & 4 \\
5 & 44 & F & Housewife & 41 & 3 \\
6 & 62 & F & Retailer & 56 & 6 \\
7 & 59 & M & Engineer & 51 & 8 \\
8 & 62 & F & Piano player & 56 & 6 \\
9 & 60 & F & Secretary & 20 & 40 \\
10 & 44 & M & Physician & 38 & 6 \\
11 & 41 & M & Guitar player & 40 & 1 \\
12 & 52 & M & Teacher & 44 & 8 \\
13 & 56 & F & Book keeper & 46 & 10 \\
14 & 28 & M & Physician & 23 & 5 \\
15 & 57 & M & Court stenographer & 53 & 4 \\
16 & 47 & M & Teacher & 42 & 5 \\
17 & 49 & M & Clerk & 35 & 14 \\
18 & 32 & F & Clarinet player & 28 & 4 \\
19 & 29 & F & Accountant & 25 & 4 \\
Mean & 46 & & & 38 & 7 \\
\hline
\end{tabular}




\begin{tabular}{ll}
\hline Case No & Clinical classification \\
\hline 1 & $\begin{array}{c}\text { Dystonic WC non localised both } \\
\text { hands, wrist flexion involuntary } \\
\text { movement }\end{array}$ \\
2 & Dystonic WC non-localised \\
3 & $\begin{array}{l}\text { Dystonic WC localised piano, } \\
\text { guitar }\end{array}$ \\
4 & $\begin{array}{l}\text { Dystonic WC localised guitar, } \\
\text { typing }\end{array}$ \\
5 & $\begin{array}{c}\text { Dystonic WC non-localised writing, } \\
\text { typing }\end{array}$ \\
6 & Dystonic WC non localised
\end{tabular}

$7 \quad$ Dystonic WC non-localised eating
Simple piano player's cramp

$$
\begin{aligned}
& \text { Dystonic WC non-localised typing, } \\
& \text { hand writing }
\end{aligned}
$$

$$
\text { Dystonic WC localised guitar }
$$
playing

Simple WC guitar playing

$$
\begin{aligned}
& \text { Dystonic WC non-localised writing- } \\
& \text { drawing }
\end{aligned}
$$

Dystonic WC localised writing

Simple WC operating

$$
\begin{aligned}
& \text { Simple WC stenographer's cramp } \\
& \text { typing }
\end{aligned}
$$

Dystonic non-localised handwriting

Simple non-localised handwriting

Simple localised clarinet playing

$$
\begin{aligned}
& \text { Simple WC non localised } \\
& \text { handwriting }
\end{aligned}
$$

Major clinical complaint

Right: lack of control of the thumb; general tightness of the wrist. Left: tendency to wrist flexion when writing with the left hand.

Spasms in hyperextension and in some cases hyperabduction (thumb) in the right hand.

Flexion spasms in left 3rd, 4th and 5th fingers when playing piano, guitar, or writing.

Flexion spasms in right 4th and 5th fingers, eventually $3 \mathrm{rd}$, when playing guitar.

Flexion spasms in right 1 st to 5 th fingers, Holds pen in grip.

The pen was sustained with great strength an attempt to improve writing.

The pen was sustained with great strength and effort. Tightening of the whole forearm. Involuntary flexion and supination movements while writing.

Lack of control of right thumb and index. Thumb tends to adduct, flex. Index tends to bend to the palm.

Pen is sustained with great strength and effort. Tightening of the whole forearm. Involuntary movements of the hand non task-specific.

Difficulties are in controlling right index finger and thumb.

Difficult control of left index finger, which cramps in extension.

Tension in forearm and increased pressure in the whole hand.

Clenching of index and, on occasions, middle finger when writing.

Hyperextension of the thumb when writing or using scalpel.

Loss of control of fingers IV and V while typing

Tension and pain in the forearm while handwriting.

Tension in the forearm while handwriting.

Difficulties in controlling her right 4th and particularly 5th finger while playing clarinet.

Difficulty for handwriting when using the right hand. Tendency to wrist flexion and co-contraction in forearm. and effort. Tightening of the whole arm in

\section{Previous treatment}

Propranolol (irreg.), tolazoline, chlordiazepoxide, doxepin $\mathrm{HCl}$, diazepam, amitriptyline, bromocriptine, neostigmine, alprazolam, clonazepam, trihexyphenidyl. Surgery

Artane $10 \mathrm{mg} /$ day propranolol $40 \mathrm{~m}$ day. Surgery

None

Trihexyphenidyl. Surgery

Trihexyphenidyl ( $8 \mathrm{mg} /$ day) produce transitory improvement. Propramolol.

None

Trihexyphenidyl-diazepam

Surgery: right ant. interosseus $\mathrm{n}$ decompression. "Right triggeftipg release".

None

Propranolol

None

None

None

None

None

Biofeedback, psychotherapy, trihexyphenidyl

None

Trihexyphenidyl, propranolol

Hypnosis, trihexyphenidyl, diazepam

WC $=$ writer's cramp.

19 patients were described from a clinical and physiological point of view in a recent report. "Seven patients have been added to that series.

The following definitions were used following Sheehy and

Marsden ${ }^{2}$ : simple cramp (difficulty performing only one specific task); dystonic cramp (muscle spasms in several tasks); and progressive cramp (increasing difficulty in performing new tasks). We also characterised the cramps arbitrarily 


\begin{tabular}{|c|c|c|c|c|}
\hline \multicolumn{3}{|c|}{ Botulinum toxin } & \multirow{2}{*}{$\begin{array}{l}\text { Area injected } \\
\text { EI; EPL; APL } \\
\text { Idem } \\
\text { Idem } \\
\text { Idem } \\
\text { FDS IV, V }\end{array}$} & \multirow{2}{*}{$\begin{array}{l}\text { Improvement } \\
\text { Major improvement } \\
\text { Major improvement } \\
\text { Major improvement } \\
\text { Major improvement } \\
\text { Major improvement }\end{array}$} \\
\hline $\begin{array}{l}3 / 86 \\
9 / 86 \\
2 / 87 \\
5 / 87 \\
9 / 87\end{array}$ & $\begin{array}{l}55 \mathrm{U} \\
40 \mathrm{U} \\
35 \mathrm{U} \\
20 \mathrm{U} \\
10 \mathrm{U}\end{array}$ & $\begin{array}{l}\text { (3 sessions) } \\
\text { (2 sessions) } \\
\text { (1 session) } \\
\text { (1 session) } \\
\text { (1 session) }\end{array}$ & & \\
\hline $\begin{array}{l}5 / 86 \\
9 / 86 \\
1 / 87 \\
6 / 87\end{array}$ & $\begin{array}{l}19 \cdot 5 \mathrm{U} \\
25 \mathrm{U} \\
10 \mathrm{U} \\
15 \mathrm{U}\end{array}$ & $\begin{array}{l}\text { (2 sessions) } \\
\text { ( } 2 \text { sessions) } \\
(1 \text { session) } \\
(1 \text { session) }\end{array}$ & $\begin{array}{l}\text { EDC II, III, IV, V; APL; FDI } \\
\text { EDC II, III, IV, V; APL; FPL; EPL } \\
\text { EDC II, III; EPL } \\
\text { EDC II, III, IV, V; FPL; APL }\end{array}$ & $\begin{array}{l}\text { Major improvement } \\
\text { Major improvement } \\
\text { Major improvement } \\
\text { Major improvement }\end{array}$ \\
\hline $\begin{array}{r}2 / 86 \\
11 / 86\end{array}$ & $\begin{array}{l}140 \mathrm{U} \\
160 \mathrm{U}\end{array}$ & $\begin{array}{l}\text { (3 sessions) } \\
\text { (4 sessions) }\end{array}$ & $\begin{array}{l}\text { FDP III, IV, V; FDS III, IV, V } \\
\text { FDP III, IV, V; FDS III, IV, V }\end{array}$ & $\begin{array}{l}\text { Mild improvement-weakness } \\
\text { None-no weakness }\end{array}$ \\
\hline $\begin{array}{l}5 / 86 \\
9 / 86\end{array}$ & $\begin{array}{l}35 \mathrm{U} \\
60 \mathrm{U}\end{array}$ & $\begin{array}{l}\text { (3 sessions) } \\
\text { ( } 2 \text { sessions) }\end{array}$ & $\begin{array}{l}\text { FDP III, IV, v; FDS III, IV, v } \\
\text { FDP III, IV, V; FDS III, IV, V }\end{array}$ & $\begin{array}{l}\text { Major in typing; moderate in playing } \\
\text { Major in typing; moderate in playing }\end{array}$ \\
\hline \multicolumn{3}{|c|}{$\begin{array}{l}\text { continuing every month } \\
4 / 87 \quad 80 \mathrm{U} \quad \text { (3 sessions) }\end{array}$} & $\begin{array}{l}\text { FDS II, III, IV, V; FPB; FPL; } \\
\text { FDP II, III, IV, V }\end{array}$ & $\begin{array}{l}\text { Major in typing; moderate in playing } \\
\text { Moderate in writing }\end{array}$ \\
\hline $\begin{array}{r}8 / 86 \\
10 / 86 \\
1 / 87\end{array}$ & $\begin{array}{r}45 \mathrm{U} \\
110 \mathrm{U} \\
45 \mathrm{U}\end{array}$ & $\begin{array}{l}\text { (2 sessions) } \\
\text { ( } 3 \text { sessions) } \\
\text { (2 sessions) }\end{array}$ & $\begin{array}{l}\text { FDP II, III, IV; FDS II, III, IV; FPL } \\
\text { Deltoids and triceps } \\
\text { Deltoids and triceps }\end{array}$ & $\begin{array}{l}\text { None-weakness } \\
\text { Minimal subjective improvement } \\
\text { None }\end{array}$ \\
\hline $7 / 86$ & $90 \mathrm{U}$ & (3 sessions) & $\begin{array}{l}\text { FPL; FDS II, III; FCR; FCU } \\
\text { APL; EDC III; ECR; ECU }\end{array}$ & \multirow[t]{2}{*}{$\begin{array}{l}\text { Major improvement. Flexion IM disappeared } \\
\text { Supination IM improved. Decreased tension in forearm. } \\
\text { Changed posture }\end{array}$} \\
\hline $1 / 87$ & $125 \mathrm{U}$ & (3 sessions) & FCR; FCU; ECR & \\
\hline $\begin{array}{r}8 / 86 \\
10 / 86 \\
4 / 87 \\
10 / 87\end{array}$ & $\begin{array}{l}20 \mathrm{U} \\
17.5 \mathrm{U} \\
20 \mathrm{U} \\
3.75 \mathrm{U}\end{array}$ & $\begin{array}{l}\text { (2 sessions) } \\
\text { (3 sessions) } \\
\text { (3 sessions) } \\
\text { (1 session) }\end{array}$ & $\begin{array}{l}\text { FDS II; FDP II; FPL; ADD. POLL. } \\
\text { FDI; ADD. POL.; OPP. POLL. } \\
\text { FDS II; FDP II; ADD. POL. } \\
\text { FDS II }\end{array}$ & $\begin{array}{l}\text { Major improvement } \\
\text { Questionable } \\
\text { Major improvement } \\
\text { Major improvement }\end{array}$ \\
\hline $\begin{array}{l}9 / 86 \\
2 / 87 \\
6 / 87\end{array}$ & $\begin{array}{l}75 \mathrm{U} \\
92 \mathrm{U} \\
50 \mathrm{U}\end{array}$ & $\begin{array}{l}\text { (3 sessions) } \\
\text { (3 sessions) } \\
\text { (1 session) }\end{array}$ & $\begin{array}{l}\text { FPL; FDS II, III, IV; EPL; EDC II, III, IV } \\
\text { FCR; FCU } \\
\text { Idem }\end{array}$ & $\begin{array}{l}\text { Major improvement in handwriting } \\
\text { and involuntary movements non task specific }\end{array}$ \\
\hline $\begin{array}{r}12 / 86 \\
5 / 87\end{array}$ & $25 \mathrm{U}$ & $\begin{array}{l}\text { (2 sessions) } \\
(1 \text { session) }\end{array}$ & $\begin{array}{l}\text { FPL; FDP II; FDS II } \\
\text { Idem }\end{array}$ & $\begin{array}{l}\text { Major improvement after first injection } \\
\text { Major improvement after first injection }\end{array}$ \\
\hline $2 / 87$ & $67 \cdot 5 \mathrm{U}$ & (6 sessions) & EXT. IND; EDC II; FDS III & Mild improvement \\
\hline $9 / 87$ & $40 \mathrm{U}$ & (2 sessions) & FPL; FDS II, III, IV; EPL; EDC II, III, IV & Mild improvement \\
\hline $8 / 87$ & $52.5 \mathrm{U}$ & (4 sessions) & FPL; FDS II, III; FDP II & Major improvement \\
\hline $\begin{array}{r}9 / 87 \\
11 / 87\end{array}$ & $20 \mathrm{U}$ & $\begin{array}{l}\text { (2 sessions) } \\
\text { (1 session) }\end{array}$ & $\begin{array}{l}\text { EPL; APL; EPB } \\
\text { FCU }\end{array}$ & $\begin{array}{l}\text { Major improvement } \\
\text { Moderate improvement }\end{array}$ \\
\hline $9 / 87$ & $70 \mathrm{U}$ & (3 sessions) & FDS IV, V; FDP IV, V & Major improvement \\
\hline $\begin{array}{l}9 / 87 \\
1 / 88 \\
1 / 88\end{array}$ & $\begin{array}{l}40 \mathrm{U} \\
80 \mathrm{U} \\
70 \mathrm{U}\end{array}$ & $\begin{array}{l}\text { ( } 2 \text { sessions) } \\
\text { (2 sessions) } \\
\text { ( } 3 \text { sessions) }\end{array}$ & $\begin{array}{l}\text { FDS II, III, IV; FPL; EDC II, III, IV; EPL } \\
\text { FCR; ECR; FCU } \\
\text { FCR }\end{array}$ & $\begin{array}{l}\text { None-weakness } \\
\text { None-weakness } \\
\text { None-weakness }\end{array}$ \\
\hline $2 / 88$ & $5 \mathrm{U}$ & (1 session) & FDS IV-V & Major improvement \\
\hline $3 / 88$ & $20 \mathrm{U}$ & (1 session) & FCR; FCU; FPL; FDS II & Major improvement \\
\hline
\end{tabular}

by the extent of the abnormality. Cramps were "localised" if they affected up to three fingers in the same hand or "nonlocalised" if more than three fingers were affected in the same or both hands.
Patients The mean age at the time of consultation was 46 years (range between 28 and 62 years). The mean age at onset of symptoms was 38 years (range between 20 and 56 years) and the mean duration of symptoms was 7 years (range 
between 1 and 40 years). Nine patients were males and six were females (table 1).

Twelve patients had dystonic hand cramps; four of them were localised. Seven patients had simple hand cramps, two of them non-localised. Fourteen patients had their major difficulties when writing or typing, two when playing guitar, one when playing piano, one when playing the clarinet, and one (a physician) when using a scalpel (table 2). The main complaints in these patients were those of "tension, lack of control of the hand or certain fingers, and clenching of the fingers." Only one patient (case 1) had bilateral writer's cramp. Two patients (cases 7 and 9) had fast involuntary flexion movements of the wrist while performing the task triggering the cramps. Three patients (cases 3,5 and 11) had spasmodic torticollis. One patient (case 11) also had blepharospasm. Ten patients had received prior treatment for writer's cramp. Nine received pharmacological treatments including trihexyphenidyl, propranolol, diazepam and amitriptyline, and four had surgery (cervical laminectomy for a herniated disc in patient 1 , operations for "tendon dysfunction" in patients 2 and 4, and right anterior interosseous nerve decompression in patient 8). None of these treatments produced stable clinical improvement and all drugs were withdrawn at the time of starting this experimental protocol. Nine patients had not received any treatment.

Testing procedures Each time a patient was seen, the task that produced the abnormality was examined. In patients with writer's cramp, we obtained samples of handwriting. Additionally, muscle strength was tested on the standard MRC scale from $0-5^{12}$ in order to quantify degree of muscle weakness accomplished by botulinum toxin injections. Video tapes were made of the patients while they were performing the tasks triggering the cramps. EMG studies were done with previously described techniques ${ }^{11}$ before beginning therapy and were repeated when therapy was successful. EMG was recorded from the muscle groups suggested to be overactive during the neurological examination. Muscles tested most often were flexor digitorum superficialis and profundus, flexor pollicis longus, extensor digitorum communis, and extensor pollicis longus. In each recording session, agonist and antagonist muscles were tested simultaneously to determine the type of muscle activity (bursts, spasms), the agonistantagonist pattern of activity (co-contraction, alternating), and the degree of localisation of the cramps (to one or more muscles). EMG together with the clinical findings helped determine the muscles to be injected. Consequently, on occasion, some muscles injected were other than those specifically identified by EMG.

Treatment protocol Target muscles for the first injection were selected during clinical examination and the EMG study. They were identified on the basis of the abnormal movements and postures observed while performing the task triggering the cramps. Particular attention was paid to the initial abnormal movement. Initial injection of botulinum toxin type A (Oculinum) totalled less than $20 \mathrm{U}(1 \mathrm{U}=0.4 \mathrm{ng}$ = approximately 1/2,500 of human LD50). A Teflon coated hypodermic needle with a bared tip and hub was used for simultaneous injection and EMG recordings. ${ }^{13}$ Botulinum toxin was injected in the muscle belly of the target muscles under EMG monitoring of active movements and movement of the needle with passive movement of the joint. Distinctions were made between the individual finger fascicles of the larger
Cohen, Hallett, Geller, Hochberg

muscles. This technique allowed the precise location of small 으 size target muscles in an area where muscles and individual $Z$ finger fascicles are tightly packed. At the beginning of the study, injections were given close to the end plate areas of the selected muscles. End-plates were identified by either endplate spikes or noise or by observing that all recorded motor units had an initial negative phase. Once in the middle of the muscle, adjustments of only a few $\mathrm{mm}$ were required to localise the endplate area. Results indicated that the toxin diffused at least $1 \mathrm{~cm}$ since adjacent muscle fascicles could be affected (see Results). For this reason, such attention to localisation did not seem important, and later in the study we were content to inject the middle of the muscle.

There were three possible results of each injection: (1) The injection was not effective enough and the same abnormal movements and postures remained. In this case, the same muscles as in the earlier injection were reinjected. (2) The injection was effective and the patient's condition improved. In this case, the patient was not injected again until the effects of the toxin wore off. (3) The injection was effective for the target muscles but the pattern of involuntary movement was now different. In this case the muscles responsible for this new clinical pattern were injected.

Treatment was administered every 2 weeks and if necessary (when no weakness or improvement was achieved), concentrations were increased in three steps:

First week: $2 \cdot 5 \mathrm{U} / 0 \cdot 1 \mathrm{cc}$ up to a maximum of $20 \mathrm{U}$.

Third week: $2 \cdot 5$ or $5 \mathrm{U} / 0 \cdot 1 \mathrm{cc}$ up to a maximum of $40 \mathrm{U}$.

Fifth week: 5 or $10 \mathrm{U} / 0 \cdot 1 \mathrm{cc}$ up to a maximum of $80 \mathrm{U}$.

The rationale for these three steps in the administration of the first series of botulinum toxin injections was to determine the lowest dose capable of producing the desired functiona improvement for each patient. In this manner, we avoide excessive administration of toxin. The maximun accumulative dose in one series of injections used in our tria was $160 \mathrm{U}(=64 \mathrm{ng}=$ approximately $1 / 16$ th of the human LD50 (1-2 $\mu \mathrm{g}))$. The cumulative dose in the first series was used in subsequent series as a single dose.

If the dose required to benefit the patient became too high in the course of the treatment or if the patient became unresponsive, presence of antibodies against botulinum toxin was investigated. Under these criteria two patients were tested for presence of antitoxin antibodies. ${ }^{14} 15$

Follow-up Patients have been followed for up to 27 months. After functional improvement and post-treatment testing sessions, the patients were instructed to come back when they felt the presence of cramps strong enough as to produce functional impairment. We did not necessarily wait until the patients returned to their pretreatment state. At this time, the patients were reinjected in only one session with approximately the total amount given to them in the first series (which usually had consisted of two to three sessions). Often this proved to be sufficient to reproduce benefit, but at times a second or third session was again needed.

\section{Results}

\section{Illustrative case reports}

Patient 2: A 31 year old man presented with 2 years of progressive pain and "numbness" in the dorsum of the right hand only while writing. Progressively, he 


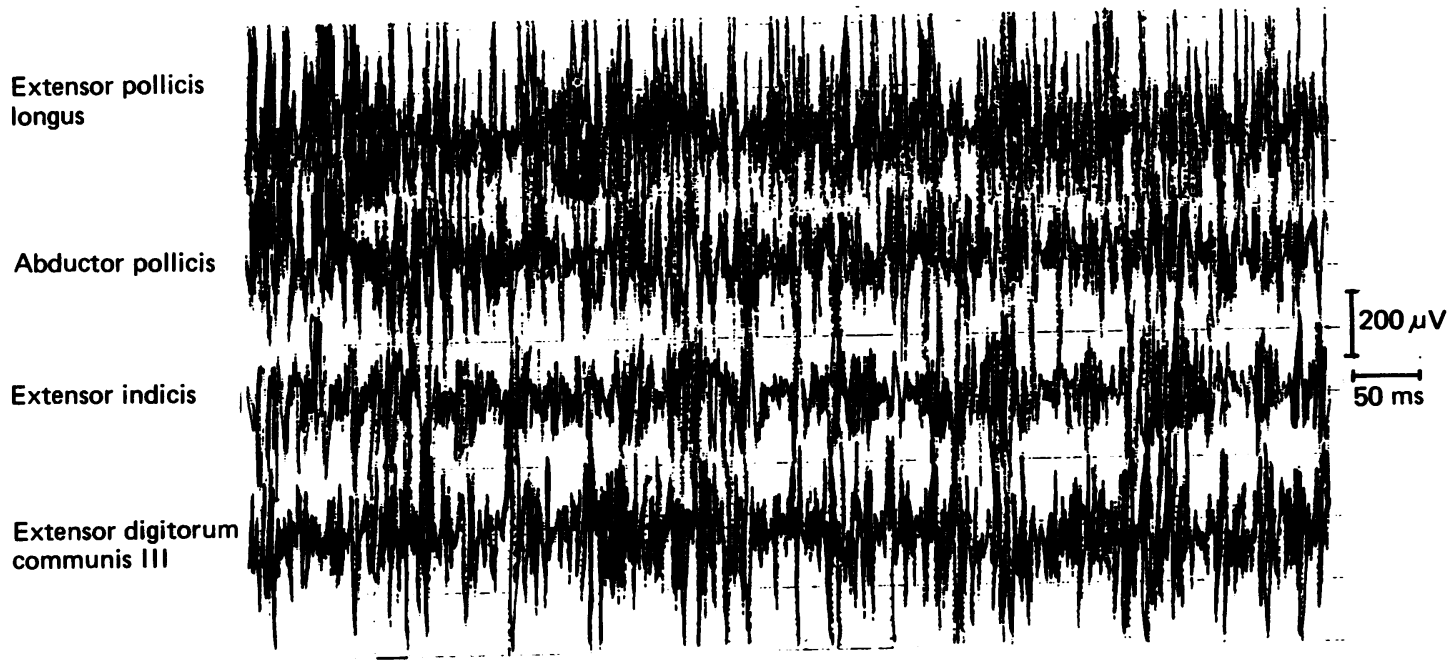

Fig 1 EMG recorded from extensor pollicis longus, abductor pollicis, extensor indicis, and extensor digitorum communis III in patient 2. Recordings were bipolar from a pair of stainless steel, Teflon coated wire electrodes introduced into the muscle bellies. EMG activity was amplified and filtered with a bandpass of 100-10,000 $\mathrm{Hz}$. Note the prolonged muscle spasms present in the different muscles tested (EMG was printed as dots from a digital EMG machine, and the dots were manually connected to improve the tracing).

developed difficulties in opening cans or bottles. He had no tremor, neck pain, shoulder or elbow complaints. One year before evaluation, he underwent an operation on his index finger " . . . to free his tendons ..." without improvement. Trihexyphenidyl (10 $\mathrm{mg} /$ day) and propranolol ( $40 \mathrm{mg} /$ day) had no effect. Examination showed decreased selectivity of independent finger movements. When writing, the first noticable event was that his index and 5th fingers extended. A few seconds later the 3rd and 4th fingers tended to curl into flexion, but soon also extended. At this point he described pain in the dorsum of his hand which projected to the wrist. There were no other abnormalities. EMG showed muscle spasms in extensor

Before treatment

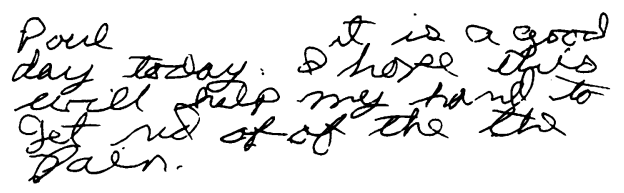

After treatment

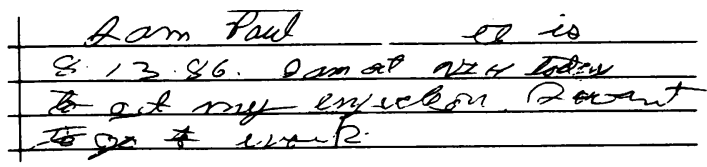

Fig 2 Handwriting sample taken before and after treatment from patient 2. pollicis longus, extensor indicis, and extensor digitorum communis III (fig 1). We interpreted the transitory curling of fingers 3 and 4 as voluntary compensation for the extensor spasms. Botulinum toxin type A (19.5 U) was injected into extensor digitorum communis II, III, IV and V, first dorsal interosseous and abductor pollicis longus. Two weeks later the patient claimed $80 \%$ improvement in his handwriting, the pain disappeared and his writing was more legible (fig 2). Muscle strength in extensor muscles decreased from 5 to between 3 and 4. EMG patterns recorded after treatment showed no differences with the pre-treatment study.

Patient 6: A 62 year old woman presented with six years of progressive difficulties in writing described as "tension" in hand, arm and shoulder. This problem progressively worsened but without affecting other activities. Examination showed tensed muscles in the right upper extremity. Attempts to perform independent finger movements were grossly distorted. She wrote very slowly and pushed the pen in towards the table. She received three different series of injections (table 2); the first in flexors of the thumb, index, middle and 4th finger without any improvement. The second and third series were given to proximal muscles (deltoids and triceps, very active while writing) but also without improvement. Muscle strength in distal muscles injected decreased from 5 to 3 . Muscle strength in proximal muscles injected decreased from 5 to 4 .

Patient 7: A 59 year old man developed mild writing 
Patient number 1
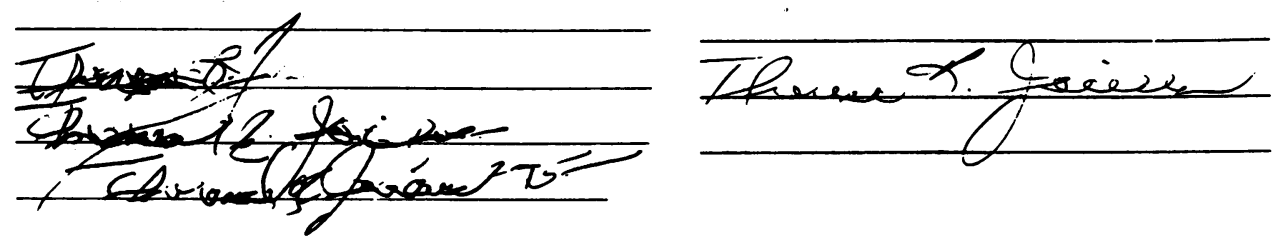

Patient number 13

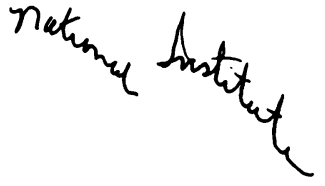

$$
\begin{aligned}
& \text { iations isustetute of thelest } \\
& \text { 1:tersed Instikent } \\
& \text { 'atemal Anetitute of Neol the }
\end{aligned}
$$

Patient number 9

$$
\begin{aligned}
& \begin{array}{l}
\&^{2}-80 \text { grems byr D-rm } \\
\text { Apt } 5 \text { - } 100 \text { t1000 }
\end{array} \\
& \text { ML heen. VA 22102 } \\
& \text { Telephone -100703-356-8765 } \\
& \text { Now is the tim for ale }
\end{aligned}
$$

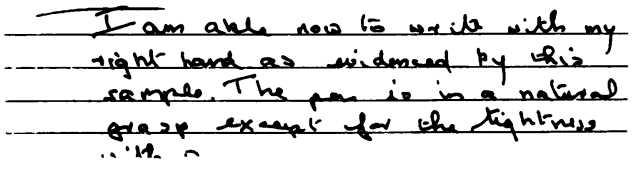

Fig 3 Examples of handwriting before and after successful treatment with botulinum toxin in three different patients with dystonic writer's cramp. Patient 1 could not write her own name and after treatment she was able to draw the letters in a more comfortable way and with improved posture. Patient 13 had intense spasms with clenching of the index and third fingers resulting in excessive slanting of the writing which was corrected after treatment. Patient 9 had serious difficulties in writing more than 3 to 4 lines because of intense muscle spasms producing pain in the forearm (see interruption in the 5th line of pretreatment writing). After treatment her handwriting improved, was smoother, and allowed her to write without experiencing prolonged muscle spasms.

difficulties 8 years before. Six months before his examination these worsened and started affecting his use of a fork. He was treated with diazepam without improvement and trihexyphenidyl, which produced some benefit but was not tolerated. While writing he described "a feeling of tension" in the right hand and wrist. At the time of his first consultation, there was tightening of finger and wrist flexors and on occasions involuntary fast supination and flexion movements of the wrist. The pen was held in an abnormal posture. EMG showed prolonged muscle spasms in both flexor and extensor muscles. Injections were given to flexor pollicis longus, flexor digitorum superficialis II and III, flexor carpi radialis and ulnaris, and abductor pollicis longus. Two weeks later, he felt slightly more relaxed, but now the complaint had changed to include extension of the wrist while writing. Injections were then given to extensor digitorum communis III, extensor carpi radialis and ulnaris. The results were improved posture when holding the pen, decreased tension in the forearm, clear decrease of involuntary movements. The patient felt much better. However, the appearance of the handwriting did not change noticably. Muscle strength in injected muscles decreased from 5 to 4. EMG patterns recorded after treatment showed no differences with the pretreatment study.

Patient 8: A 62 year old piano player noted lack of control of thumb and index finger while playing. The main problem was that the thumb tended to move in towards the hand, while the index finger bent in flexion. Over a 6 year period, this problem interfered with her profession and she underwent a right anterior interosseous nerve decompression (with uncertain indication) without improvement. The neurological examination was normal. EMG, while she repetitively tapped a piano key with the index finger showed simultaneous bursting in flexors of the thumb, second and third fingers indicating the lack of selectivity of independent finger movements. Additionally, there were no well-formed bursts in EDC II alternating with bursts in flexor muscles. In the first series of injections $20 \mathrm{U}$ of botulinum toxin were given to flexor digitorum superficialis II, profundus II, flexor pollicis longus and 




After treatment

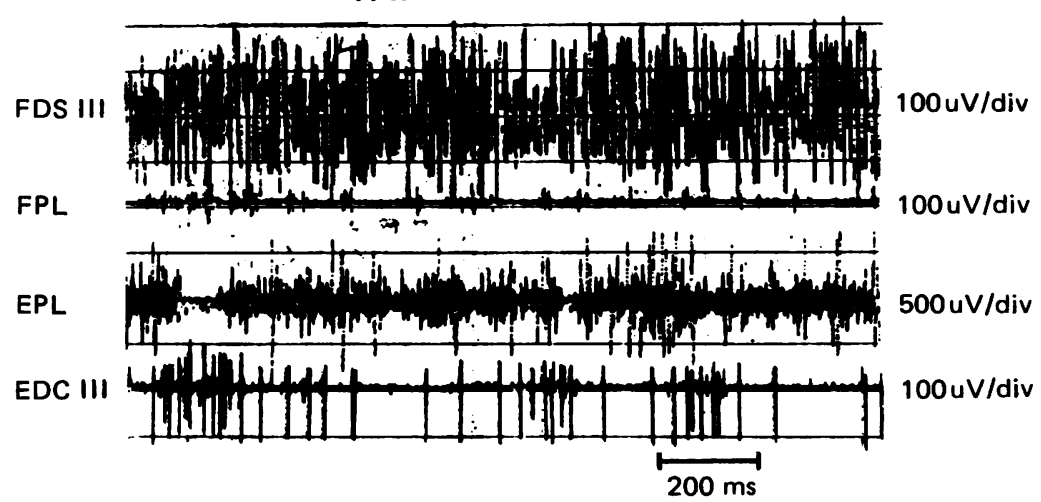

Fig 4 Examples of

electromyographic recordings while writing obtained from a patient with writer's cramp before and after successful treatment with botulinum toxin. The patient's actual handwriting improved very much with the treatment. However, muscle spasms in flexor digitorum superficialis III (FDS III) and extensor pollicis longus (EPL) did not appear to be modified (see fig 1 for explanation of tracing). adductor pollicis with a major improvement. In the second series, the patient's complaints changed and injections were given to first dorsal interosseous, adductor and opponens pollicis without effect. In a third series, reinjections in flexors of the second finger and adductor pollicis benefited the patient. In a fourth series, injections in flexor digitorum superficialis II with lower amounts (less than $5 \mathrm{U}$ ) produced clear improvement in playing (table 2). Muscle strength in flexors of the proximal interphalangeal joint of the index finger decreased from 5 to 3 when maximal improvement was experienced.

Botulinum toxin injections produced subjective functional improvement in 16 of the 19 patients treated. In most of the patients with writer's cramp, handwriting became more legible (fig 3). Patients with piano and guitar player's cramp were able to perform better. Patients with typist's cramp had less mistakes when typing.

Clinical improvement was never seen without weakness. The degree of weakness required to benefit these patients was variable from person to person. Effective total doses varied between 17.5 and $140 \mathrm{U}$ depending on the anatomical extension of the cramps and personal sensitivity to the drug. The amount of toxin required by each patient in successive series of injections has been similar to the first series for almost 2 years now. The duration of the beneficial effects of botulinum toxin in these patients was variable. Some patients remained improved for as much as 6 months (case 1), although others required reinjection every month (case 4).

As would be expected, patients with localised form of cramps and fewer muscles and fingers affected (like patient 8 ) tended to require less botulinum toxin than patients with non-localised forms (like patient 5). Interestingly, benefits were seen earlier when cramps affected primarily muscles in the extensor compartment of the forearm (like in patient 2) than in the flexor compartment. Patients with cramps in the flexor compartment and highly skilled functions deranged, as piano playing in patient 8 , required smaller doses in very specific muscle groups as flexor digitorum superficialis and profundus II, adductor pollicis, and opponens pollicis. In patient 8 , for example, the injection of an additional muscle not directly affected as first dorsal interosseus (injected in the second series, table 2) led to worsening of the motor performance. This situation was resolved afterwards by carefully avoiding this muscle and injecting particularly FDS II 
and FDP II.

We found that injection into particular fascicles of a muscle (for example, flexor digitorum superficialis II) weakened also flexion function in neighbouring finger muscles (thumb or III). This effect was seen only in muscles less than 1-2 cm distant from the injection. The effect could also apply to deep flexor muscles after injection of deep extensor muscles that are close, just across the interosseous membrane. This could be due to local spread of the toxin.

Side effects of the injections included weakness restricted to the functions mediated by the muscles treated. We have seen no systemic effects of the injections except for the two patients who developed asymptomatic antibodies against botulinum toxin (cases 3 and 4). Patient 3, for example, had improved after the first series of injections requiring $140 \mathrm{U}$, but after remission 9 months later, $160 \mathrm{U}$ were not enough to reduce his symptoms. Subsequent evaluation indicated that he developed antibodies against botulinum toxin type A. The only apparent "symptom" of the antibody development in both cases was the inability to respond to further injections.

Post treatment EMGs were performed in eight patients. EMG findings included fibrillations and positive sharp waves and low amplitude incomplete interference patterns. Muscle spasms, and lack of reciprocal inhibition in antagonist muscles were present in both pre and post EMGs and no certain changes in these features were recognised (fig 4). These findings suggest that injections did not modify the physiologic mechanisms responsible for the prolonged muscle bursts and lack of reciprocal inhibition.

\section{Discussion}

This study provides preliminary evidence that botulinum toxin is helpful in treating many patients with hand cramps. Improvement in performance is associated with some degree of weakness. But the opposite, weakness, was not necessarily associated with improved performance. Our impression is that it is necessary to achieve an equilibrium in each patient between sufficient weakness to reduce spasm but not so much as to hamper function. This equilibrium ideally should improve patients' faulty performances without affecting other functions.

To achieve these goals, two conditions should be fulfilled: ( $a$ ) the lowest effective doses should be given, and $(b)$ the injection point should be standardised, so as to make sure that the drug will reach the end plate area of the target muscles similarly in successive reinjections. The first condition is important in order to minimise the doses injected. By gradually increasing the dose in the first series we accomplished the two goals of injecting only what the patient needed and standardising the doses for subsequent series of injec- 으 tions. The second condition is also important and was $z$ satisfied in this trial by injecting the toxin approximately in the middle of the muscle belly, where endplate areas are located. This approach was certainly good enough in patients with non-localised type $\theta$ of writer's cramps (cases 2 and 9), since it is conceivable for the toxin to spread to a certain extent from the injection points. This spread in muscles tightly packed like those in the forearm would allow the migration of the drug from the injected muscle to neighbouring ones. Since the cramps in these patients affected many extensor or flexor muscles, it is not worrisome. However, there is another group of patients better exemplified in our trial by patient 8 . She was a piano $\frac{\bar{N}}{\vec{D}}$

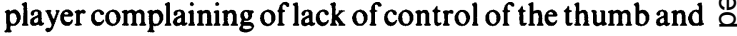
index finger while performing. In her case injections had to be more precise in order to hit only the right $\vec{\circ}$ muscles. Any spread or injection to neighbouring muscles worsened her condition. Such patients do not $\vec{\omega}$ require a large amount of toxin, but small doses administered very precisely to specific muscles.

In a recent study of 19 patients with hand cramps ${ }^{11}$ ? we found that five elements identified by physiological on investigation are indicative of impaired motor contrap $\omega$ in these patients: co-contraction of antagonist mus్ cles, tremor, prolongation of EMG bursts, lack of selectivity in attempts to perform independent finge movements and failure of willed activity to occur. The $\vec{z}$ comparison of EMG recordings before and after successful treatment with botulinum toxin did na show evident changes in pattern. They still showed. $\vec{\theta}$ prolonged bursts of muscle activity, loss of reciprocal $\infty$ inhibition, tremor, and lack of selectivity in attempts to perform independent finger movements. However, the amplitude of recordings from injected muscles seemed to be lower than before treatment. These findings demonstrate that the therapy has not eliminated the spasms, but that prolonged EMG bursts in a weak muscle do not necessarily lead to clinical spasms. $\overrightarrow{\overrightarrow{0}}$ More important, these physiological findings give 3 some explanation of the clinical observation that these patients' performances improve very much after treatment, but do not return to normal (particularly patients with musician's cramps). The motor control disorder is still present. There may be some quan- $:$ titative effect on the spasms such as a reduction in the 3 . percentage of the motoneuron pool participating in a spasm or a reduction in the frequency of muscle bursts, but such observations would be difficult to make.

The findings reported here suggest that botulinum toxin may be useful in the treatment of hand cramps. More definitive results require both the development of objective rating scales and double blind studies. Or Objective rating scales are not easy to devise in order $N$ to characterise writing or the quality of playing a 
musical instrument. One possibility would be to measure the time required to write a certain phrase or to draw a spiral. However, improvement in these patients cannot always be measured in terms of speed to perform. For example, patient 7 was more relaxed and returned to a normal posture of the hand as a consequence of botulinum toxin injections, but the quality and speed of his handwriting never changed. A double blind study would not be difficult to do, but the fact that many initial injections that did not produce weakness did not produce benefit can be taken as some evidence against these results as being simply a placebo effect.

We thank Drs Lederman, Einbinder, Newmark, Schnek, Bailey, and Sirdofsky for kindly referring their patients, and Dr Hatheway for determining the presence of antibodies against botulinum toxin in two of our patients.

\section{References}

1 Newmark J, Hochberg FH. Isolated painless manual incoordination in 57 musicians. $J$ Neurol Neurosurg Psychiatry 1987;50:291-5.

2 Sheehy MP, Marsden CD. Writer's cramp-a focal dystonia. Brain 1982;105:461-80.

3 Critchley M. In: Critchley M, Henson RA, eds. Music and the brain. Studies on the neurology of music. London: Heinemann, 1977.

4 Crisp AH, Moldofsky H. A psychosomatic study of writer's cramp. Br J Psychiatry 1965;111:841-58.

5 Beech HR. In: Eysenck HJ, ed. Behaviour therapy and the neuroses: Readings in modern methods of treatment derived from learning theory. Oxford: Pergamon Press, 1960:349-72.

6 Bindman E, Tibbetts RW. Writer's cramp, a rational approach to treatment? $B r J$ Psychiatry 1977;131: 143-8.

7 Lang AET, Sheehy MP, Marsden CD. Acute anticholinergic action in focal dystonia. Adv Neurol 1983;37: 193-200.

8 Scott AB, Kennedy RA, Stubbs HA. Botulinum A toxin injection as a treatment for blepharospasm. Arch Ophthalmol 1985;103:347-50.

9 Ludlow CL, Naunton RF, Sedory SE, Schultz GM, Hallett M. Effects of botulinum toxin injections on speech in adductor spasmodic dysphonia. Neurology 1988;38:1220-5.

10 Tsui JK, Eisen A, Stoessl AJ, Calne S, Calne DB. Doubleblind study of botulinum toxin in spasmodic torticollis. Lancet 1986;ii:245-7.

11 Cohen LG, Hallett M. Hand cramps: clinical features and electromyographic patterns in a focal dystonia. Neurology 1988;38:1005-12.

12 Medical Research Council. Aids to the Examination of the Peripheral Nervous System. Memorandum 45. Crown. London: HMSO, 1976.

13 Miller RH, Woodson GE, Jankovic J. Botulinum toxin injection of the vocal fold for spasmodic dysphonia: a preliminary report. Arch Otolaryngol Head Neck Surg 1987;113:603-5.

14 Hatheway CH, Snyder JD, Seals JE, Edell TA, Lewis Jr GE. Antitoxin levels in botulism patients treated with trivalent equine botulism antitoxin to toxin types A, B, and E. $J$ Infect Dis 1984;150:407-12.

15 Cardella MA. Botulinum toxois. In: Lewis KH, Cassel K Jr, eds. Botulism: Proceedings of a Symposium. PHS Publication. Washington DC: Government Printing Office, 1964:113-30. 